\title{
Experimental Studies on the Irradiation of Facial Bones in Animals: A Review
}

\author{
Lucas Poort1,2, Bernd Lethaus1,2,3, Roland Böckmann1, Doke Buurman1, Jos De Jong2,4, \\ Frank Hoebers ${ }^{2,4}$, Peter Kessler ${ }^{1,2}$ \\ ${ }^{1}$ Department of Cranio- and Maxillofacial Surgery, Maastricht University Medical Centre, Maastricht, \\ The Netherlands \\ ${ }^{2}$ GROW School for Oncology and Developmental Biology, Maastricht University Medical Centre, Maastricht, \\ The Netherlands \\ ${ }^{3}$ Department of Oral- and Maxillofacial Surgery, Universitätsklinikum Aachen (University Medical Centre), \\ Aachen, Germany \\ ${ }^{4}$ Department of Radiation Oncology (Maastro Clinic), Maastricht University Medical Centre, Maastricht, \\ The Netherlands \\ Email: l.poort@mumc.nl
}

Received 24 February 2014; revised 22 March 2014; accepted 20 April 2014

Copyright $@ 2014$ by authors and Scientific Research Publishing Inc. This work is licensed under the Creative Commons Attribution International License (CC BY). http://creativecommons.org/licenses/by/4.0/

\section{(c) (i) Open Access}

\section{Abstract}

Introduction: Radiotherapy is often used to treat head and neck malignancies, with inevitable effects on the surrounding healthy tissues. We have reviewed the literature concerning the experimental irradiation of facial bones in animals. Materials and Methods: A PubMed search was performed to retrieve animal experiments on the irradiation of facial bones that were published between January 1992 and January 2012. The search terms were "irradiation facial bone" and "irradiation osteoradionecrosis". Results: Thirty-six publications were included. The irradiation sources were Cobalt ${ }^{60}$, orthovoltage, 4 - 6 megavolt photons, and brachytherapy. The total dose varied between 8 - $60 \mathrm{~Gy}$ in single or multiple fractions. The literature presents a broad range of animal studies that differ in terms of the in vivo model, irradiation, observation period, and evaluation of results. Discussion: The different animal models used leave many questions unanswered. A detailed and standardized description of the methodology and results would facilitate the comparability of future studies.

\section{Keywords}

Irradiation, Animal Experiments, Facial Bones, Osteoradionecrosis 


\section{Introduction}

For head and neck malignancies, current treatment regimes frequently include (chemo-)radiotherapy. Several clinical studies have shown the beneficial effects of radiotherapy as a primary, definitive treatment or when used in a postoperative setting after surgical resection, with respect to the time to recurrence or survival [1]-[4]. However, despite improved radiotherapeutic techniques such as intensity-modulated radiation therapy (IMRT) [5]-[9], irradiation effects on the surrounding healthy tissue continue to cause complications of different severities [10]-[13].

One complication is osteoradionecrosis (ORN), which can affect all bony structures in the head and neck region but is most commonly seen in the mandible, at a frequency of $2 \%-22 \%$ [14] [15]. The diagnosis is generally based on clinical presentation. ORN is defined as "irradiated bone, which becomes devitalized and is exposed through the overlying skin or mucosa and does not heal within a period of three months, without tumor recurrence" [16]. Several factors have been identified that increase the risk of developing ORN, including treatment-related factors such as the radiation dose and volume of irradiation [14] [16]. ORN can be triggered by surgical intervention or pressure sores from dentures or can occur spontaneously. It can arise at any point after irradiation therapy, even several years later [17].

The treatment of ORN ranges from conservative management, with or without surgical debridement, to broad resection in severe cases. Due to the compromised local tissue condition, this treatment is often followed by reconstruction with free microsurgical flap surgery, which is a major surgical intervention [18]-[20].

The pathophysiology of ORN and the effect of irradiation on bones were extensively described by Marx as a complex metabolic homeostatic deficiency of tissue that is created by radiation-induced cellular injury. Marx hypothesizes that a sequence of irradiation, formation of hypoxic-hypocellular-hypovascular tissue, and breakdown of tissue driven by persistent hypoxia can cause a chronic nonhealing wound [16] [17]. Histological evaluations show progressive vascular damage that causes endarteritis, thrombosis, and fibrosis [17] [21] [22].

In addition, Delanian et al. state that radiation-induced fibrosis accounts for the damage observed in normal tissues, including bone, after radiotherapy. The key event in this type of damage consists of the activation and deregulation of fibroblastic activity, which leads to the formation of atrophic tissue. The destruction of endothelial cells coupled with vascular thrombosis leads to the necrosis of microvessels, local ischemia, and tissue loss [16].

The irradiated bone remains fragile and may be subject to surges of late reactivated inflammation after a physicochemical trauma, resulting in a tendency to develop ORN. The mandible is thought to be predisposed to the development of ORN principally as the result of the fibrosis, which causes the obliteration of the inferior alveolar artery and the inability of the facial artery to act as an alternative blood supply [16] [23].

The above-mentioned hypotheses on the pathogenesis of structural changes in bone after irradiation are mainly based on human studies. Definite answers to many questions, however, remain elusive such as the following: How much irradiation is tolerated before necrosis develops? Is there a maximum radiation dose and an optimum time frame to ensure a successful surgical intervention? What is the fractionation sensitivity (in other words, the alpha/beta ratio) of the bone? Are there some preventive measures that can be taken to prevent ORN? What is the clinical relevance of a radiologic diagnosis of ORN? Does teeth extraction before treatment increase or decrease the risk of ORN? In an effort to better understand the biological changes that occur in facial bones after irradiation, we have reviewed studies investigating the irradiation of facial bones in animal models.

We found that the literature presents a broad variety of animal studies that differ in terms of the animal model, applied dose, radiation source, observation period, and evaluation of results. We made an effort to evaluate all these models and determine whether they answer any of the questions given above. Furthermore, we aim to make a recommendation on how to optimize future studies to increase translational value and comparability.

\section{Materials and Methods}

A PubMed search was performed for animal studies that involved the irradiation of facial bones and were published between January 1992 and January 2012. The search terms used were "irradiation facial bone" and "irradiation osteoradionecrosis," and the limit activation term was "animal".

The year of publication, experimental setup, irradiation source, irradiation dose, irradiation fractionation, kind and number of animals used, type of intervention, and radiological and histological examinations were recorded. Only studies for which the full-text publications were available were included. References of the articles found 
were checked regarding importance and obtained when useful.

Research questions were: What animal model was used? What irradiation scheme was used? What intervention was studied? What was the method of evaluation? What were the results? And what is the clinical implication?

\section{Results}

The search resulted in 152 publications, which included reviews and case reports. Case reports were discarded. Based on the abstracts, we reviewed the full text of 48 potentially relevant publications and included 36 publications for this review (Appendix). The flow chart of the selection is given in Figure 1.

The publications that were excluded lacked radiological and histological evaluations of the irradiation or involved only in vitro cell cultures. The irradiation details of the included studies are shown in Table 1.

\subsection{Animal Species, Age, and Gender}

The animals that were used in the studies are summarized in Table 2. The animals were exclusively adult in 21 studies (58\%) and immature animals in nine studies. In the remaining six studies, age was not specified. Male animals were used in 11 studies, and female animals were used in four studies. The majority of the studies did not specify the gender of the animals.

\subsection{Irradiation Source}

The irradiation sources were Cobalt (Co) 60 in 11 studies, orthovoltage in 10 studies, 4 - 6-megavolt (MV) photons in eight studies (18 MV in two studies), and high-dose-rate (HDR) brachytherapy in four studies. One study did not mention the source of irradiation. No study used concomitant chemo-radiotherapy.

\subsection{Dose and Fractionation}

Of the schemes mentioned, 11 studies (31\%) had a single fraction scheme with a dose ranging from 8 to 35 Gray (Gy), of which four had a brachytherapeutic source. The frequency varied from 1 to 27 fractions, and the dose

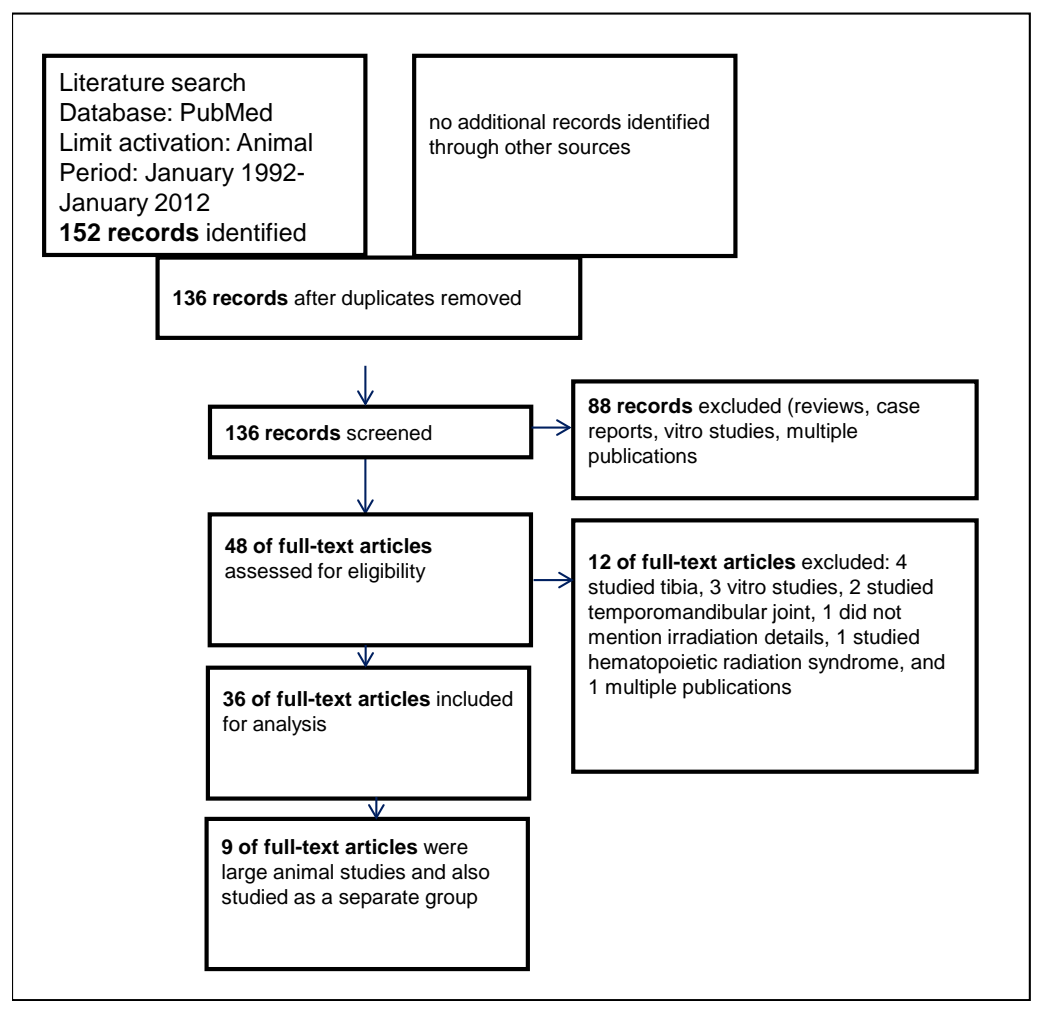

Figure 1. The flow diagram of all studies considered, excluded and included. 
Table 1. Irradiation details of the included studies.

\begin{tabular}{|c|c|c|c|c|c|c|c|}
\hline Study & Fraction dose (gray) & Frequency & Interval & Total dose (gray) & Equivalent dose (gray) & Source & Animal \\
\hline 1 & 8 & 3 & $1 \mathrm{w}$ & 24 & $64^{* *}$ & Co60 & Minpig \\
\hline 2 & $5.9 / 7 / 8.89$ & 5 & $1 \mathrm{~d}$ & $29.5 / 35 / 44.5$ & $50 / 64 / 96^{* *}$ & Ortho & Rat \\
\hline 3 & $5.9 / 7 / 8.89$ & 5 & $1 d$ & $29.5 / 35 / 44.5$ & $50 / 64 / 96^{* *}$ & Ortho & Rat \\
\hline 4 & 30 & 1 & & 30 & & Brachy & Rat \\
\hline 5 & 30 & 1 & & 30 & & $18 \mathrm{MV}$ & Rabbit \\
\hline 6 & $6.5-9$ & 5 & $1 \mathrm{w}$ & $32.5-45.4$ & $60-108$ & $18 \mathrm{MV}$ & Rabbit \\
\hline 7 & 3.6 & 10 & $1 d$ & 36 & & Ortho & Rat \\
\hline 8 & 8 & 1 & & 8 & & Co60 & Rat \\
\hline 9 & 3.6 & 10 & $1 \mathrm{~d}$ & 36 & & Ortho & Rat \\
\hline 10 & 5.7 & 4 & $\mathrm{~nm}$ & 22.8 & 50 & Co60 & Dog \\
\hline 11 & 15 & 1 & & 15 & 46 & Co60 & Rabbit \\
\hline 12 & $15 / 25 / 35$ & 1 & & $15 / 25 / 35$ & & Ortho & Rabbit \\
\hline 13 & 30 & 1 & & 30 & & Ortho & Rabbit \\
\hline 14 & $4 \& 5$ & $10 \& 15$ & $1 d^{*}$ & $40 / 50 / 60$ & & $6 \mathrm{MV}$ & Dog \\
\hline 15 & 4.3 & 10 & $1 d$ & 43 & & Co60 & Dog \\
\hline 16 & 5.6 & 4 & $2 \mathrm{x} / \mathrm{w}$ & 22.4 & 50 & $4 \mathrm{MV}$ & Rabbit \\
\hline 17 & 5.6 & 4 & $2 \mathrm{x} / \mathrm{w}$ & 22.4 & 50 & $4 \mathrm{MV}$ & Rabbit \\
\hline 18 & 5.6 & 4 & $2 \mathrm{x} / \mathrm{w}$ & 22.4 & 50 & $4 \mathrm{MV}$ & Rabbit \\
\hline 19 & 11.96 & 6 & $3 \mathrm{x} / \mathrm{w}$ & 71.4 & & Ortho & Rabbit \\
\hline 20 & 3 & 15 & $2-3 d$ & 45 & 50 & $6 \mathrm{MV}$ & Sheep \\
\hline 21 & 5.4 & 5 & $2 \mathrm{~d}$ & 27 & 50 & $6 \mathrm{MV}$ & Rabbit \\
\hline 22 & 5.5 & 5 & $1 \mathrm{w}$ & 27.5 & & $6 \mathrm{MV}$ & Rabbit \\
\hline 23 & 20 & 1 & & 20 & 45 & Brachy & Rat \\
\hline 24 & 20 & 1 & & 20 & 45 & Brachy & Rat \\
\hline 25 & 15 & 4 & $2 w$ & 60 & & $6 \mathrm{MV}$ & Rat \\
\hline 26 & 6 & 7 & $2-3 d$ & 42 & & Ortho & Rat \\
\hline 27 & 4.3 & 10 & $1 \mathrm{~d}$ & 43 & & Co60 & Dog \\
\hline 28 & 2.5 & 20 & $1 \mathrm{~d}$ & 50 & & Co60 & Dog \\
\hline 29 & 4.3 & 10 & $1 \mathrm{~d}$ & 43 & 60 & Co60 & Dog \\
\hline 30 & 15 & 1 & & 15 & & Co60 & Rabbit \\
\hline 31 & 2 & 16 & $4 \mathrm{x} / \mathrm{w}$ & 32 & & Ortho & Rabbit \\
\hline 32 & 4 & 10 & $3 \mathrm{x} / \mathrm{w}$ & 40 & & Co60 & Dog \\
\hline 33 & $2.5 / 3$ & $18 / 15$ & $\mathrm{~nm}$ & 45 & & Co60 & Rat \\
\hline 34 & 2 & 27 & $1 d$ & 54 & 54 & $\mathrm{~nm}$ & Dog \\
\hline 35 & 20 & 1 & & 20 & & Brachy & Rat \\
\hline 36 & 20 & 1 & & 20 & & Ortho & Rat \\
\hline
\end{tabular}

given varied from 2 to 35 Gy. In 10 studies (28\%), the fractions were given daily. Four studies had a one-week interval or more, and one study had 10 and 15 fractions given daily for a week with a one-month interval between irradiation periods.

The total dose varied from 8 to 60 Gy. The equivalent dose, when mentioned, was between 45 and 108 Gy. 


\subsection{Irradiation Target}

The mandible was irradiated in 34 studies, and the maxilla was included in one study. In three studies, the zygomatico-orbital complex was irradiated (Table 3).

\subsection{Intervention}

The interventions studied were distraction osteogenesis in eleven studies. Distraction osteogenesis is creating new bone from callus. The callus is formed in an artificial bone gap that is gradually being widened using an implanted "distraction" device. In eleven studies, no intervention was performed. In other studies, the extraction of teeth, placement of dental implants, or bone transplantation into a defect combined with irradiation was studied. The interventions studied are listed in Table 3 and Table 4.

\subsection{Radiological Evaluation}

In 11 studies, plain X-ray films and dental films were used for the radiological examinations of the irradiated bone. Four studies performed a growth analysis in non-adult growing animals on a lateral scull radiograph, five studies used micro-computed tomography (micro-CT), three studies used conventional CT images, and five studies conducted X-ray examinations of the histological sections only. Three studies evaluated the bone density using CT data, and one study performed a dual-energy X-ray absorptiometry scan. No study used magnetic resonance (MR) imaging. The timing of the radiological evaluation is listed in Table 5.

\subsection{Radiological Findings}

Studies that evaluated growth in general found growth retardation after irradiation. Studies that evaluated new bone formation following a distraction procedure reported a delay in bone formation after irradiation. Several studies produced radiographic images of the histological slides of implants and bone, thereby providing a useful evaluation of the ingrowth of dental implants. No study mentioned radiographic signs of ORN, such as erosion of the cortex, bone sequesters, or pathological fractures.

\subsection{Histological Evaluation}

The histological staining method of the bone was most frequently hematoxylin/eosin (17 studies) and toluidine blue (six studies) staining. Some studies used multiple staining procedures. Three studies used scanning electron microscopy, and three studies used immunohistochemical analyses. Ten studies used a fluorochrome analysis of bone turnover. Often, the bone was embedded in poly(methyl methacrylate) and processed because this treatment allows for a good analysis of bone architecture and integration of dental implants. The timing of the histological evaluation is listed in Table 5.

\subsection{Histological Findings}

Several studies used semi-quantitative methods of histological evaluation, including evaluation of lacunar nucleation (empty lacunae), osteoblast/osteoclast ratio, osteocyte count, fibrosis, the presence of lamellar or woven bone, and osteoid volume. After irradiation, most studies using smaller animals reported increased fibrosis, decreased numbers of osteocytes, less vascularization, and less mature bone in distraction studies. No study reported bone necrosis.

Table 2. Animal species used in the included studies.

\begin{tabular}{ccc}
\hline Animal & Number of studies & Percentage \\
\hline Rat & 13 & $36 \%$ \\
Rabbit & 13 & $36 \%$ \\
Dog & 8 (5 beagle) & $22 \%$ \\
Pig & 1 & $3 \%$ \\
Sheep & 1 & $3 \%$ \\
\hline
\end{tabular}


Table 3. Irradiation target, side, and intervention.

\begin{tabular}{|c|c|c|c|c|c|c|c|}
\hline Study & $\begin{array}{l}\text { Control } \\
\text { group }\end{array}$ & Total dose (gray) & Source & Animal & Irradiation target & $\begin{array}{l}\text { Irradiation side } \\
\text { (s) }\end{array}$ & Intervention \\
\hline 1 & + & 24 & Co60 & Minpig & $\begin{array}{l}\text { Mandible and } \\
\text { maxilla }\end{array}$ & Bilateral & Implantology \\
\hline 2 & - & $29.5 / 35 / 44.5$ & Ortho & Rat & Mandible & Left & $\begin{array}{l}\text { Mechanical } \\
\text { test }\end{array}$ \\
\hline 3 & - & 29.5/35/44.5 & Ortho & Rat & Mandible & Left & Histology only \\
\hline 4 & + & 30 & Brachy & Rat & Mandible & Left & Extraction \\
\hline 5 & - & 30 & $18 \mathrm{MV}$ & Rabbit & Mandible & Bilateral & $\begin{array}{l}\text { Bone } \\
\text { transplant }\end{array}$ \\
\hline 6 & - & $32.5-45.4$ & $18 \mathrm{MV}$ & Rabbit & Mandible & Left & DO unilateral \\
\hline 7 & + & 36 & Ortho & Rat & Mandible & Left & DO unilateral \\
\hline 8 & + & 8 & Co60 & Rat & Mandible & Left & Extraction \\
\hline 9 & + & 36 & Ortho & Rat & Mandible & Left & DO unilateral \\
\hline 10 & + & 22.8 & Co60 & Dog & Mandible & Unilateral & DO unilateral \\
\hline 11 & + & 15 & Co60 & Rabbit & Mandible & Right & Implantology \\
\hline 12 & + & $15 / 25 / 35$ & Ortho & Rabbit & $\begin{array}{l}\text { Zygomatico orbital } \\
\text { complex }\end{array}$ & Right & Growth only \\
\hline 13 & + & 30 & Ortho & Rabbit & $\begin{array}{l}\text { Zygomatico orbital } \\
\text { complex }\end{array}$ & Right & Growth only \\
\hline 14 & + & $40 / 50 / 60$ & $6 \mathrm{MV}$ & Dog & Mandible & Bilateral & Implantology \\
\hline 15 & + & 43 & Co60 & Dog & Mandible & Bilateral & Implantology \\
\hline 16 & + & 22.4 & $4 \mathrm{MV}$ & Rabbit & Mandible & Bilateral & DO unilateraal \\
\hline 17 & + & 22.4 & $4 \mathrm{MV}$ & Rabbit & Mandible & Bilateral & DO unilateraal \\
\hline 18 & + & 22.4 & $4 \mathrm{MV}$ & Rabbit & Mandible & Bilateral & DO unilateraal \\
\hline 19 & + & 71.4 & Ortho & Rabbit & $\begin{array}{l}\text { Zygomatico orbital } \\
\text { complex }\end{array}$ & Right & Growth only \\
\hline 20 & + & 45 & $6 \mathrm{MV}$ & Sheep & Mandible & Bilateraal & DO unilateraal \\
\hline 21 & - & 27 & $6 \mathrm{MV}$ & Rabbit & Mandible & Unilateral & DO bilateral \\
\hline 22 & + & 27.5 & $6 \mathrm{MV}$ & Rabbit & Mandible & Left & DO unilateraal \\
\hline 23 & + & 20 & Brachy & Rat & Mandible & Right & Injection $\mathrm{GF}^{*}$ \\
\hline 24 & + & 20 & Brachy & Rat & Mandible & Right & Histology only \\
\hline 25 & + & 60 & $6 \mathrm{MV}$ & Rat & Mandible & Left & Histology only \\
\hline 26 & + & 42 & Ortho & Rat & Mandible & $\mathrm{nm}$ & Histology only \\
\hline 27 & + & 43 & Co60 & Dog & Mandible & Bilateral & Implantology \\
\hline 28 & - & 50 & Co60 & Dog & Mandible & $\mathrm{nm}$ & DO unilateraal \\
\hline 29 & + & 43 & Co60 & Dog & Mandible & Bilateral & Implantology \\
\hline 30 & - & 15 & Co60 & Rabbit & Mandible & Left & Implantology \\
\hline 31 & + & 32 & Ortho & Rabbit & Mandible & Left & $\begin{array}{c}\text { Bone } \\
\text { transplant }\end{array}$ \\
\hline 32 & + & 40 & Co60 & Dog & Mandible & $\begin{array}{l}\text { Uni- and } \\
\text { bilateral }\end{array}$ & $\begin{array}{l}\text { Bone } \\
\text { transplant }^{\#}\end{array}$ \\
\hline 33 & + & 45 & Co60 & Rat & Mandible & Bilateral & Bone defect \\
\hline 34 & + & 54 & $\mathrm{~nm}$ & Dog & Mandible & $\mathrm{nm}$ & $\begin{array}{c}\text { Bone } \\
\text { transplant }\end{array}$ \\
\hline 35 & - & 20 & Brachy & Rat & Mandible & Left & Extraction \\
\hline 36 & + & 20 & Ortho & Rat & Mandible & Left & Growth only \\
\hline
\end{tabular}

$\mathrm{DO}=$ distraction osteogenesis, $\mathrm{GF}=$ growth factors being $(\mathrm{BMP}-2$ and or $\mathrm{bFGF}),{ }^{*}=\mathrm{HA}$ granules ${ }^{\wedge}=$ biphasic calcium phosphate granules, $\mathrm{nm}=$ not mentioned. 
Table 4. Interventions performed in the included studies.

\begin{tabular}{ccc}
\hline Intervention & Number of studies & Percentage \\
\hline Distraction osteogenesis & 11 & $31 \%$ \\
Extractions of teeth & 3 & $8 \%$ \\
Extractions and dental implant placement & 7 & $19 \%$ \\
Bone transplantation & $4^{*}$ & $11 \%$ \\
None & 11 & $31 \%$ \\
\hline
\end{tabular}

${ }^{*}=$ of these four studies two studies used artificial bone replacement materials.

Table 5. Irradiation target, intervention, evaluation and timing of evaluation.

\begin{tabular}{|c|c|c|c|c|c|c|}
\hline Study & $\begin{array}{l}\text { Total dose } \\
\text { (gray) }\end{array}$ & Source & Animal & Intervention & Evaluation & $\begin{array}{l}\text { Time after } \\
\text { irradiation }\end{array}$ \\
\hline 1 & 24 & Co60 & Minpig & Implantology & Radiology & 3 months \\
\hline 2 & $29.5 / 35 / 44.5$ & Ortho & Rat & Mechanical test & - & 56 days \\
\hline 3 & $29.5 / 35 / 44.5$ & Ortho & Rat & Histology only & Histology & 56 days \\
\hline 4 & 30 & Brachy & Rat & Extraction & Radiology and histology & 28 days \\
\hline 7 & 36 & Ortho & Rat & DO unilateral & Histology & 8 weeks \\
\hline 8 & 8 & Co60 & Rat & Extraction & Histology & 10,12 days \\
\hline 9 & 36 & Ortho & Rat & DO unilateral & Radiology & 8 weeks \\
\hline 10 & 22.8 & Co60 & Dog & DO unilateral & Radiology and histology & 5.5 month \\
\hline 13 & 30 & Ortho & Rabbit & Growth only & Radiology & 14 weeks \\
\hline 14 & $40 / 50 / 60$ & $6 \mathrm{MV}$ & Dog & Implantology & Radiology and histology & 12 months \\
\hline 15 & 43 & Co60 & Dog & Implantology & Radiology and histology & 5, 8 months \\
\hline 16 & 22.4 & $4 \mathrm{MV}$ & Rabbit & DO unilateral & Radiology and histology & 13 weeks \\
\hline 17 & 22.4 & $4 \mathrm{MV}$ & Rabbit & DO unilateral & Radiology & 13 weeks \\
\hline 18 & 22.4 & $4 \mathrm{MV}$ & Rabbit & DO unilateral & Histology & 13 weeks \\
\hline 19 & 71.4 & Ortho & Rabbit & Growth only & Radiology & 21 weeks \\
\hline 20 & 45 & $6 \mathrm{MV}$ & Sheep & DO unilateral & Radiology and histology & $\begin{array}{c}60 \\
\text { dayspostoperative @ }\end{array}$ \\
\hline 26 & 42 & Ortho & Rat & Histology only & Histology & 85, 141, 253 days \\
\hline 27 & 43 & Co60 & Dog & Implantology & Radiology and histology & 5, 8 months \\
\hline 28 & 50 & Co60 & Dog & DO unilateral & Radiology and histology & 9.5 months \\
\hline 29 & 43 & Co60 & Dog & Implantology & Radiology and histology & 5 and 8 months \\
\hline 30 & 15 & Co60 & Rabbit & Implantology & Radiology and histology & $62,69,83,111$ days \\
\hline 31 & 32 & Ortho & Rabbit & Bone transplant ${ }^{\wedge}$ & Radiology and histology & 19 weeks \\
\hline 32 & 40 & Co60 & Dog & Bone transplant ${ }^{\#}$ & Radiology and histology & $0,1,2,3$ months \\
\hline 33 & 45 & Co60 & Rat & Bone defect & Histology & 6, 8 weeks \\
\hline 34 & 54 & $\mathrm{~nm}$ & Dog & Bone transplant & Radiology and histology & 4 weeks \\
\hline 35 & 20 & Brachy & Rat & Extraction & Radiology and histology & 28 days \\
\hline 36 & 20 & Ortho & Rat & Growth only & Radiology and histology & 30, 60 days \\
\hline
\end{tabular}

$\mathrm{DO}=$ distraction osteogenesis, GF = growth factors being (BMP-2 and or bFGF), ${ }^{\#}=$ HA granules, ${ }^{\wedge}=$ biphasic calcium phosphate granules, $\mathrm{nm}=$ not mentioned, ${ }^{*}=7,14,30,60,90$ days after implant placement which was after 3,6 and 12 months after irradiation, ${ }^{@}=21$ days after surgery irradiation started for 35 days. 
Of the nine studies that used larger animals, including dogs and sheep, the histological findings were evaluated in detail (studies marked in gray in Table 1, Table 3, and Table 5).

\subsection{Effects of 50 Gy (Equivalent Dose Comparable to the Irradiation Protocol Used in Humans Using 2 Gy Fractions)}

Most studies used a 50 Gy equivalent dose. One study using Co60 irradiation and distraction osteogenesis found more immature bone in the distraction area after irradiation but found distraction osteogenesis to be feasible in the irradiated mandible 3 and 6 months after irradiation [24] [25].

A study using $6 \mathrm{MV}$ photon irradiation and distraction osteogenesis found significantly fewer osteoid surfaces in the regenerated bone, and there was less exuberant callus formation. However, the time of sacrifice was early, only 39 days after the beginning of irradiation treatment [26].

\subsection{Effects of 60 Gy (Equivalent Dose Comparable to Irradiation Protocol Used in Humans Using 2 Gy Fractions)}

Two studies that used Co60 irradiation with a reported equivalent dose of 60 Gy using 2 Gy fractions and implant placement reported that only three (3\%) of the 88 implants placed were mobile. There was no significant difference in the ingrowth of the implants in the bone between the experimental group and the control group. There were no empty lacunae, but the marrow showed strong connective tissue replacement, and arteriolar thrombosis was observed 5 - 8 months after irradiation [27] [28].

In the study using $6 \mathrm{MV}$ photon irradiation with a reported equivalent dose of $60 \mathrm{~Gy}$, all implants were mobile and lost over a period of 12 months after irradiation [29].

\section{Discussion}

\subsection{Animal Choice}

The use of rat and rabbit models in most studies seems to be sufficient for an initial experimental evaluation, but their comparability to the biology of human bone remains a matter of discussion. Small animals are known to have more rapid skeletal regeneration and higher bone turnover rates. In rodents, the skeleton continuously grows and reshapes. Their growth plates remain open, and Haversian remodeling, as occurs in humans, does not occur. Haversian remodeling is a type of bone turnover with tunneling osteoclasts followed by osteoblasts forming new bone, continuously crossing the bone. Rabbits exhibit Haversian remodeling, but they have a very fatty marrow that is distinctly different from human bone marrow [30]. In addition, the biology of sheep and human bone is different. Sheep bones consist mostly of a primary bone structure, unlike the largely secondary (remodeled) bones found in humans [31]. Larger animals (for example, dogs and Göttingen minipigs) are more suitable than smaller animals for studies on bone biology because they are more comparable to human patients [31] [32]. According to Reinwald, minipig bone composition and remodeling resemble human bone biology better than those of the dog bone model [33]. Additionally, the structural blood supply of the mandibles of Göttingen minipigs is comparable to that of humans. In both species, the inferior alveolar artery is the main feeding vessel of the body of the mandible and is located centrally in the bone. There are only a few anastomoses with the periosteal vessels and facial artery. This renders the bone of the mandible vulnerable to vascular damage following irradiation [32].

The age of the animals should be adjusted for the study purpose. In general, head and neck oncological patients are adults, and therefore, the age of the experimental animals should be comparable.

\subsection{Irradiation Protocol}

Of the radiation sources that were used in the different studies, orthovoltage irradiation and, to a lesser extent, Co60 irradiation, have an inferior dose distribution quality compared with 4 - 6 MV irradiation; however, these sources are adequate for the irradiation of smaller animals. In humans, the most common irradiation source is currently 4 to $6 \mathrm{MV}$ photons [11].

For example, an irradiation schedule using conventional radiation therapy or IMRT involving 35 daily exposures of $2 \mathrm{~Gy}$ each gives a total dose of $70 \mathrm{~Gy}$, which is a common treatment schedule for patients with head and neck cancer [2] [34] [35]. However, in an animal experiment, it is nearly impossible to irradiate the animals ac- 
cording to this schedule because the animals would require daily general anesthesia for immobilization. Therefore, a compromise is usually made in reducing the number of fractions and increasing the fraction dose. The formula that is used to calculate this conversion is based on the linear quadratic model [35]. For bone, the alpha/beta ratio is approximately three [27] [36] [37]. Most studies mention the equivalent dose of the irradiation schedule compared with conventional human radiotherapy using 2 Gy fractions, but only two studies mention the calculation used [27] [37].

In addition, some studies used a brachytherapeutic source with a far higher maximum dose and a significant dose fall-off.

An equivalent dose of approximately $50 \mathrm{~Gy}$ was typically used and was applied near the mandible. This is a relatively low dose, which explains the lack of radiological evidence of irradiation damage and the relatively mild histological changes observed in these studies.

Despite the difficulties with irradiation schedules in animals, we believe that the most accurate way to simulate standard human irradiation is to apply not one but at least two fractions and to avoid acute cellular damage by using a very high irradiation dose.

Of the facial bones studied, the mandible was emphasized for two reasons. First, this bone is most often present in the irradiation field in treatments of head and neck malignancies. Second, because of its dense bone tissue and specific vascular supply, the mandible is very susceptible to ORN. However, other facial bones receive irradiation too and can develop ORN [38] [39], and therefore, there is a need to study the effects of irradiation on these bones as well. In our search, we identified studies on the zygomatico-orbital complex that evaluated growth but did not evaluate histological changes. No study compared the changes in other facial bones before and after irradiation. A direct comparison would most clarify our understanding of the mechanism causing a higher incidence of ORN in the mandible compared with other facial bones.

All studies used some type of control. Seven studies performed a unilateral irradiation with a non-irradiated control side but without a separate control group. We believe that there might be an effect on the non-irradiated side, which could be partially irradiated. It is more useful to have a separate control group, as was the case in the other 28 studies.

\subsection{Radiological Evaluation}

In the distraction studies, the radiological evaluations generally revealed that the calcification of the distracted bone was delayed after irradiation. Studies that evaluated implant placement found more pronounced peri-implant bone loss after irradiation.

All studies show only minimal tissue changes. This is possibly because the radiological evaluation is generally performed relatively shortly after irradiation, usually after four to eight weeks. In eight studies, the specimens were evaluated six months after irradiation. Another explanation for the lack of radiological changes is that, as in humans, only $2 \%-22 \%$ of the test animals develop ORN after irradiation.

According to Verdonck [40], bone mineral density increases on radiological evaluation following irradiation. Conversely, O'Donovan et al. mentioned a decrease in the mineral density of bone [41]. One would of course expect a decrease in mineral density considering the seized bone formation. However, these contradicting findings in the absence of a clear understanding of the biological changes after irradiation warrants further investigation.

No study used MR imaging to identify the changes in bone marrow due to irradiation. MR imaging, however, is the investigation method of choice, as shown in human studies [42] [43].

\subsection{Histological Evaluation}

Histological evaluations were recorded in most studies. However, different variables and schemes were used for the semi-quantitative evaluations, making comparisons among studies impossible. The heterogeneous group of studies using different animal species, different irradiation sources, and different irradiation schedules makes direct comparisons highly problematic.

Interestingly, the large-animal experiments clearly showed differences between irradiation sources: after applying a 60 Gy equivalent dose in MV-irradiated animals, all implants were lost [26], whereas in the experiment using cobalt [24] [25], only three of 88 implants were lost in the Co60-irradiated bone. Despite the apparently clear difference, it must be taken into account that different dose calculation and setups can explain the relevant 
differences. There were several histological changes that were attributed to the irradiation treatment and were more pronounced in the MV experiments. However, no empty lacunae were observed in the large animal studies, most likely because the histological evaluations were performed too early or the irradiation dose was too low. Empty lacunae arise from hypoxia because of fibrosis of the bone marrow and thrombosis with endarteritis, which is a late effect of irradiation.

Describing histological results is difficult, and the use of semi-quantitative methods helps to standardize the results. Despite the helpful scoring system of Heiple (modified by Zhang), inter-and intra-observer variability remains a problem when comparing the results of different studies [44]. The parameters used were empty lacunae or osteocyte counts and, to a lesser extent, marrow fibrosis. These parameters should be used in a standardized manner in future studies to facilitate comparability, as shown by Fenner et al. [37]. Despite the large number of studies evaluated, it is not possible to directly compare these studies in detail because they were descriptive in nature.

The questions posed earlier remain mostly unanswered due to the different animal models, applied radiation dose, irradiation source, observation period, and evaluation of results.

However, some clinical implications of the results from these studies can be found: implants placed in irradiated bone with a equivalent dose of 60 Gray have a poor success rate compared to 50 Gray, implants placed before irradiation have a higher success rate compared to implants placed after irradiation, distraction osteogenesis seems feasible after irradiation, Amifostine clearly preserves cell function after irradiation, and Hyperbaric Oxygen therapy is reported to have some beneficial effects.

Based on this review, we designed an experiment that started in 2012 to develop an animal model for osteoradionecrosis. The results of this experiment will be published in the near future. Since January 2012, several new studies have been published on the irradiation of facial bones. For now, these studies do not fundamentally change our view on this subject, but they will be discussed further in our future publications.

\section{Recommendations}

Based on these studies we can recommend the following: when designing a new animal experiment on the irradiation of facial bones, one should take several factors into account. Large animals, such as dogs and minipigs, should be used for translational research when comparing the results to those of human patients. The ideal irradiation source is $6 \mathrm{MV}$ photons. There should be at least two fractions. Because irradiation effects on bone are late effects, at least three months should pass, preferably longer, before performing radiological and histological evaluations.

In histological evaluations, quantitative and semi-quantitative measurements should include osteocyte counts and assessments of marrow fibrosis.

In radiological evaluations, the plain X-ray and CT examinations should be performed after enough time has passed, at least three months, to be able to observe radiological changes of the bone caused by irradiation. It would furthermore be best to evaluate radiological changes of the bone marrow following irradiation with MR imaging, as this is considered to be the gold standard.

Future research should aim to find radioprotectants minimizing radiation damage to the bone and prevent ORN. Experimental investigation of ORN treatment with pentoxiphilin and tocopherol protocol by Delenian can further help us to understand the pathophysiology and refine the treatment of ORN.

\section{Acknowledgements}

We kindly thank professor Lambin for his valuable comments on our manuscript.

\section{Competing Interests}

None declared.

\section{References}

[1] Klug, C., Wutzl, A., Kermer, C., et al. (2005) Preoperative Radiochemotherapy and Radical Resection for Stages II-IV Oral and Oropharyngeal Cancer: Outcome of 222 Patients. International Journal of Oral and Maxillofacial Surgery, 35, 143-148. http://dx.doi.org/10.1016/j.ijom.2004.04.003 
[2] Paximadis, P.A., Christensen, M.E., Dyson, G., et al. (2012) Up-Front Neck Dissection Followed by Concurrent Chemoradiation in Patients with Regionally Advanced Head and Neck Cancer. Head and Neck, 34, 1798-1803. http://dx.doi.org/10.1002/hed.22011

[3] Ramaekers, B.L., Pijls-Johannesma, M., Joore, M.A., et al. (2011) Systematic Review and Meta-Analysis of Radiotherapy in Various Head and Neck Cancers: Comparing Photons, Carbon-Ions and Protons. Cancer Treatment Reviews, 37, 185-201. http://dx.doi.org/10.1016/j.ctrv.2010.08.004

[4] Egelmeer, A.G., Velazquez, E.R., de Jong, J.M., et al., (2011) Development and Validation of a Nomogram for Prediction of Survival and Local Control in Laryngeal Carcinoma Patients Treated with Radiotherapy Alone: A Cohort Study Based on 994 Patients. Radiotherapy and Oncology, 100, 108-115. http://dx.doi.org/10.1016/j.radonc.2011.06.023

[5] Studer, G., Studer, S.P., Zwahlen, R.A., et al. (2006) Osteoradionecrosis of the Mandible: Minimized Risk Profile Following Intensity-Modulated Radiation Therapy (IMRT). Strahlentherapie und Onkologie, 182, 283-288. http://dx.doi.org/10.1007/s00066-006-1477-0

[6] Ramaekers, B.L., Joore, M.A., Grutters, J.P., et al. (2011) The Impact of Late Treatment-Toxicity on Generic HealthRelated Quality of Life in Head and Neck Cancer Patients after Radiotherapy. Oral Oncology, 47, 768-774. http://dx.doi.org/10.1016/j.oraloncology.2011.05.012

[7] Christianen, M.E., Langendijk, J.A., Westerlaan, H.E., van de Water, T.A. and Bijl, H.P. (2011) Delineation of Organs at Risk Involved in Swallowing for Radiotherapy Treatment Planning. Radiotherapy and Oncology, 101, 394-402. http://dx.doi.org/10.1016/j.radonc.2011.05.015

[8] Overgaard, J. (2011) Hypoxic Modification of Radiotherapy in Squamous Cell Carcinoma of the Head and Neck-A Systematic Review and Meta-Analysis. Radiotherapy and Oncology, 100, 22-32.

http://dx.doi.org/10.1016/j.radonc.2011.03.004

[9] Ben-David, M.A., Diamante, M., Radawski, J.D., et al. (2007) Lack of Osteoradionecrosis of the Mandible after Intensity-Modulated Radiotherapy for Head and Neck Cancer: Likely Contributions of Both Dental Care and Improved Dose Distributions. International Journal of Radiation Oncology and Biological Physics, 68, 396-402. http://dx.doi.org/10.1016/j.ijrobp.2006.11.059

[10] Lee, J. and Moon, C. (2011) Current Status of Experimental Therapeutics for Head and Neck Cancer. Experimental Biology in Medicine (Maywood), 236, 375-389. http://dx.doi.org/10.1258/ebm.2010.010354

[11] Thariat, J., Bolle, S., Demizu, Y., et al. (2011) New Techniques in Radiation Therapy for Head and Neck Cancer: IMRT, CyberKnife, Protons, and Carbon Ions, Improved Effectiveness and Safety? Impact on Survival? Anticancer Drugs, 22, 596-606. http://dx.doi.org/10.1097/CAD.0b013e328340fd2b

[12] Mul, V.E., de Jong, J.M., Murrer, L.H., et al. (2012) L'hermitte Sign and Myelopathy after Irradiation of the Cervical Spinal Cord in Radiotherapy Treatment of Head and Neck Cancer. Strahlentherapie und Onkologie, 188, 71-76. http://dx.doi.org/10.1007/s00066-011-0010-2

[13] Boomsma, M.J., Bijl, H.P. and Langendijk, J.A. (2011) Radiation-Induced Hypothyroidism in Head and Neck Cancer Patients: A Systematic Review. Radiotherapy and Oncology, 99, 1-5. http://dx.doi.org/10.1016/j.radonc.2011.03.002

[14] Teng, M.S. and Futran, N.D. (2005) Osteoradionecrosis of the Mandible. Current Opinion Otolaryngology, Head and Neck Surgery, 13, 217-221. http://dx.doi.org/10.1097/01.moo.0000170527.59017.ff

[15] Grabenbauer, G.G., Rodel, C., Brunner, T., et al. (2001) Interstitial Brachytherapy with Ir-192 Low-Dose-Rate in the Treatment of Primary and Recurrent Cancer of the Oral Cavity and Oropharynx. Review of 318 Patients Treated between 1985 and 1997. Strahlentherapy und Onkologie, 177, 338-344. http://dx.doi.org/10.1007/PL00002416

[16] Lyons, A. and Ghazali, N. (2008) Osteoradionecrosis of the Jaws: Current Understanding of Its Pathophysiology and Treatment. British Journal of Oral and Maxillofacial Surgery, 46, 653-660. http://dx.doi.org/10.1016/j.bjoms.2008.04.006

[17] Marx, R.E. and Johnson, R.P. (1987) Studies in the Radiobiology of Osteoradionecrosis and Their Clinical Significance. Oral Surgery, Oral Medicine, Oral Pathology, 64, 379-390. http://dx.doi.org/10.1016/0030-4220(87)90136-8

[18] Jereczek-Fossa, B.A. and Orecchia, R. (2002) Radiotherapy-Induced Mandibular Bone Complications. Cancer Treatment Reviews, 28, 65-74. http://dx.doi.org/10.1053/ctrv.2002.0254

[19] Jacobson, A.S., Buchbinder, D., Hu, K. and Urken, M.L. (2010) Paradigm Shifts in the Management of Osteoradionecrosis of the Mandible. Oral Oncology, 46, 795-801. http://dx.doi.org/10.1016/j.oraloncology.2010.08.007

[20] Notani, K., Yamazaki, Y., Kitada, H., et al. (2003) Management of Mandibular Osteoradionecrosis Corresponding to the Severity of Osteoradionecrosis and the Method of Radiotherapy. Head and Neck, 25, 181-186. http://dx.doi.org/10.1002/hed.10171

[21] Bras, J., de Jonge, H.K. and van Merkesteyn, J.P. (1990) Osteoradionecrosis of the Mandible: Pathogenesis. American Journal of Otolaryngology, 11, 244-250. http://dx.doi.org/10.1016/0196-0709(90)90084-9 
[22] Marx, R.E. and Tursun, R. (2012) Suppurative Osteomyelitis, Bisphosphonate Induced Osteonecrosis, Osteoradionecrosis: A Blinded Histopathologic Comparison and Its Implications for the Mechanism of Each Disease. International Journal of Oral and Maxillofacial Surgery, 41, 283-289. http://dx.doi.org/10.1016/j.ijom.2011.12.016

[23] Zhuang, Q.W., Zhang, Z.Y., Fu, H.H., He, J. and He, Y. (2011) Does Radiation-Induced Fibrosis Have an Important Role in Pathophysiology of the Osteoradionecrosis of Jaw? Medical Hypotheses, 77, 63-65. http://dx.doi.org/10.1016/j.mehy.2011.03.024

[24] Liu, Y.X., Liu, G.C., Liu, Y.P. and Lin, X.J. (2010) Character of Distracted Bone in Irradiated Canine Mandibles and Electrophysiological Changes in the Inferior Alveolar Nerve. British Journal of Oral and Maxillofacial Surgery, 48, 115-120. http://dx.doi.org/10.1016/j.bjoms.2009.03.013

[25] Gantous, A., Phillips, J.H., Catton, P. and Holmberg, D. (1994) Distraction Osteogenesis in the Irradiated Canine Mandible. Plastic and Reconstructive Surgery, 93, 164-168. http://dx.doi.org/10.1097/00006534-199401000-00025

[26] Girod, A., Roger, T., Breton, P. and Bouletreau, P. (2005) Experimental Study of Mineralization in Mandibular Bone Distraction with Irradiation during the Consolidation Phase. Journal of Cranio-Maxillofacial Surgery, 33, 386-394. http://dx.doi.org/10.1016/j.jcms.2005.07.005

[27] Brogniez, V., D’Hoore, W., Grégoire, V., Munting, E. and Reychler, H. (2000) Implants Placed in an Irradiated Dog Mandible: A Morphometric Analysis. International Journal of Oral and Maxillofacial Implants, 15, 511-518.

[28] Brasseur, M., Brogniez, V., Grégoire, V., et al. (2006) Effects of Irradiation on Bone Remodelling around Mandibular Implants: An Experimental Study in Dogs. International Journal of Oral and Maxillofacial Surgery, 35, 850-855. http://dx.doi.org/10.1016/j.ijom.2006.03.016

[29] Asikainen, P., Klemetti, E., Kotilainen, R., et al. (1998) Osseointegration of Dental Implants in Bone Irradiated with 40, 50 or 60 Gy Doses. An Experimental Study with Beagle Dogs. Clinical Oral Implants Research, 9, 20-25. http://dx.doi.org/10.1034/j.1600-0501.1998.090103.x

[30] Muschler, G.F., Raut, V.P., Patterson, T.E., Wenke, J.C. and Hollinger, J.O. (2010) The Design and Use of Animal Models for Translational Research in Bone Tissue Engineering and Regenerative Medicine. Tissue Engineering Part B: Reviews, 16, 123-145. http://dx.doi.org/10.1089/ten.teb.2009.0658

[31] Pearce, A.I., Richards, R.G., Milz, S., Schneider, E. and Pearce, S.G. (2007) Animal Models for Implant Biomaterial Research in Bone: A Review. European Cell Materials, 13, 1-10.

[32] Saka, B., Wree, A., Anders, L. and Gundlach, K.K.H. (2002) Experimental and Comparative Study of the Blood Supply to the Mandibular Cortex in Göttingen Minipigs and in Man. Journal of Cranio-Maxillofacial Surgery, 30, 219225. http://dx.doi.org/10.1054/jcms.2002.0305

[33] Reinwald, S. and Burr, D. (2008) Review of Nonprimate, Large Animal Models for Osteoporosis Research. Journal of Bone Mineral Research, 23, 1353-1368. http://dx.doi.org/10.1359/jbmr.080516

[34] Rusthoven, K.E., Raben, D., Ballonoff, A., Kane, M., Song, J.I. and Chen, C.H. (2008) Effect of Radiation Techniques in Treatment of Oropharynx Cancer. The Laryngoscope, 118, 635-639.

http://dx.doi.org/10.1097/MLG.0b013e31815fdf0e

[35] Fowler, J.F. (2010) 21 Years of Biologically Effective Dose. British Journal of Radiology, 83, 554-568. http://dx.doi.org/10.1259/bjr/31372149

[36] Fowler, J.F., Tome, W.A., Fenwick, J.D. and Mehta, M.P. (2004) A Challenge to Traditional Radiation Oncology. International Journal of Radiation Oncology, Biology, Physics, 60, 1241-1256. http://dx.doi.org/10.1016/j.ijrobp.2004.07.691

[37] Fenner, M., Park, J., Schulz, N., et al. (2010) Validation of Histologic Changes Induced by External Irradiation in Mandibular Bone. An Experimental Animal Model. Journal of Cranio-Maxillofacial Surgery, 38, 47-53. http://dx.doi.org/10.1016/j.jcms.2009.07.011

[38] Lim, A.A., Karakla, D.W. and Watkins, D.V. (1999) Osteoradionecrosis of the Cervical Vertebrae and Occipital Bone: A Case Report and Brief Review of the Literature. American Journal of Otolaryngology, 20, 408-411. http://dx.doi.org/10.1016/S0196-0709(99)90083-2

[39] Yoo, J.S., Rosenthal, D.I., Mitchell, K. and Ginsberg, L.E. (2010) Osteoradionecrosis of the Hyoid Bone: Imaging Findings. American Journal of Neuroradiology, 31, 761-766. http://dx.doi.org/10.3174/ajnr.A1892

[40] Verdonck, H.W., Meijer, G.J., Nieman, F.H., Stoll, C., Riediger, D. and De Baat, C. (2008) Quantitative Computed Tomography Bone Mineral Density Measurements in Irradiated and Non-Irradiated Minipig Alveolar Bone: An Experimental Study. Clinical Oral Implants Research, 19, 465-468. http://dx.doi.org/10.1111/j.1600-0501.2007.01496.x

[41] O’Donovan, D.A., Yeung, I., Zeman, V., Neligan, P.C., Pang, C.Y. and Forrest, C.R. (2001) Radiation-Induced Craniofacial Bone Growth Inhibition: Development of an Animal Model. Journal of Craniofacial Surgery, 12, 533-543. http://dx.doi.org/10.1097/00001665-200111000-00006 
[42] Støre, G., Smith, H.J. and Larheim, T.A. (2000) Dynamic MR Imaging of Mandibular Osteoradionecrosis. Acta Radiologica, 41, 31-37. http://dx.doi.org/10.1258/rsmacta.41.1.31

[43] Rabin, B.M., Meyer, J.R., Berlin, J.W., Marymount, M.H., Palka, P.S. and Russell, E.J. (1996) Radiation-Induced Changes in the Central Nervous System and Head and Neck. Radiographics, 16, 1055-1072. http://dx.doi.org/10.1148/radiographics.16.5.8888390

[44] Zhang, W.B., Zheng, L.W., Chua, D. and Cheung, L.K. (2010) Bone Regeneration after Radiotherapy in an Animal Model. Journal of Oral and Maxillofacial Surgery, 68, 2802-2809. 


\section{Appendix}

\section{Studies Included}

[1] Verdonck, H.W., Meijer, G.J., Laurin, T., et al. (2007) Assessment of Vascularity in Irradiated and Nonirradiated Maxillary and Mandibular Minipig Alveolar Bone Using Laser Doppler Flowmetry. The International Journal of Oral \& Maxillofacial Implants, 22, 774-778.

[2] Tchanque-Fossuo, C.N., Monson, L.A., Farberg, A.S., et al. (2011) Dose-Response Effect of Human Equivalent Radiation in the Murine Mandible: Part II. A Biomechanical Assessment. Plastic \& Reconstructive Surgery, 128, 480e487e. http://dx.doi.org/10.1097/PRS.0b013e31822b67ae

[3] Tchanque-Fossuo, C.N., Monson, L.A., Farberg, A.S., et al. (2011) Dose-Response Effect of Human Equivalent Radiation in the Murine Mandible: Part I. A Histomorphometric Assessment. Plastic \& Reconstructive Surgery, 128, 114121. http://dx.doi.org/10.1097/PRS.0b013e31821741d4

[4] Cohen, M., Nishimura, I., Tamplen, M., et al. (2011) Animal Model of Radiogenic Bone Damage to Study Mandibular Osteoradionecrosis. American Journal of Otolaryngology, Head and Neck Medicine and Surgery, 32, 291-300. http://dx.doi.org/10.1016/j.amjoto.2010.06.001

[5] Yachouh, J., Breton, P., Roux, J.P. and Goudot, P. (2010) Osteogenic Capacity of Vascularised Periosteum: An Experimental Study on Mandibular Irradiated Bone in Rabbits. Journal of Plastic, Reconstructive \& Aesthetic Surgery, 63, 2160-2167. http://dx.doi.org/10.1016/j.bjps.2010.01.015

[6] Zhang, W.B., Zheng, L.W., Chua, D. and Cheung, L.K. (2010) Bone Regeneration after Radiotherapy in an Animal Model. Journal of Oral and Maxillofacial Surgery, 68, 2802-2809. http://dx.doi.org/10.1016/j.joms.2010.04.024

[7] Inyang, A.F., Schwarz, D.A., Jamali, A.M. and Buchman, S.R. (2010) Quantitative Histomorphometric Assessment of Regenerate Cellularity and Bone Quality in Mandibular Distraction Osteogenesis after Radiation Therapy. Journal of Craniofacial Surgery, 21, 1438-1442. http://dx.doi.org/10.1097/SCS.0b013e3181ec693f

[8] Hosokawa, Y., Sakakura, Y., Tanaka, L., Okumura, K., Yajima, T. and Kaneko, M. (2007) Effects of Local and Whole Body Irradiation on Appearance of Osteoclasts during Wound Healing of Tooth Extraction Sockets in Rats. Journal of Radiation Research, 48, 273-280. http://dx.doi.org/10.1269/jrr.06069

[9] Fregene, A., Jing, X.L., Monson, L.A. and Buchman, S.R. (2009) Alteration in Volumetric Bone Mineralization Density Gradation Patterns in Mandibular Distraction Osteogenesis Following Radiation Therapy. Plastic \& Reconstructive Surgery, 124, 1237-1244. http://dx.doi.org/10.1097/PRS.0b013e3181b5a42f

[10] Liu, Y.X., Liu, G.C., Liu, Y.P. and Lin, X.J. (2010) Character of Distracted Bone in Irradiated Canine Mandibles and Electrophysiological Changes in the Inferior Alveolar Nerve. British Journal of Oral and Maxillofacial Surgery, 48, 115-120. http://dx.doi.org/10.1016/j.bjoms.2009.03.013

[11] Matsui, Y., Ohno, K., Michi, K. and Tachikawa, T. (1994) Histomorphometric Examination of Healing around Hydroxylapatite Implants in ${ }^{60}$ Co-Irradiated Bone. British Journal of Oral and Maxillofacial Surgery, 52, 167-172. http://dx.doi.org/10.1016/0278-2391(94)90403-0

[12] O’Donovan, D.A., Yeung, I., Zeman, V., Neligan, P.C., Pang, C.Y. and Forrest, C.R. (2001) Radiation-Induced Craniofacial Bone Growth Inhibition: Development of an Animal Model. Journal of Craniofacial Surgery, 12, 533-543. http://dx.doi.org/10.1097/00001665-200111000-00006

[13] Forrest, C.R., O’Donovan, D.A., Yeung, I., et al. (2002) Efficacy of Radioprotection in the Prevention of Radiation-Induced Craniofacial Bone Growth Inhibition. Plastic \& Reconstructive Surgery, 109, 1311-1324. http://dx.doi.org/10.1097/00006534-200204010-00015

[14] Asikainen, P., Klemetti, E., Kotilainen, R., et al. (1998) Osseointegration of Dental Implants in Bone Irradiated with 40, 50 or 60 Gy Doses. An Experimental Study with Beagle Dogs. Clinical Oral Implants Research, 9, 20-25. http://dx.doi.org/10.1034/j.1600-0501.1998.090103.x

[15] Brogniez, V., Nyssen-Behets, C., Grégoire, V., Reychler, H. and Lengelé, B. (2002) Implant Osseointegration in the Irradiated Mandible. A Comparative Study in Dogs with a Microradiographic and Histologic Assessment. Clinical Oral Implants Research, 13, 234-242. http://dx.doi.org/10.1034/j.1600-0501.2002.130302.x

[16] Muhonen, A., Muhonen, J., Lindholm, T.C., et al. (2002) Osteodistraction of a Previously Irradiated Mandible with or without Adjunctive Hyperbaric Oxygenation: An Experimental Study in Rabbits. International Journal of Oral and Maxillofacial Surgery, 31, 519-524. http://dx.doi.org/10.1054/ijom.2002.0257

[17] Muhonen, A., Muhonen, J., Minn, H., et al. (2002) The Effects of Irradiation and Hyperbaric Oxygen on Bone Formation during Rabbit Mandibular Distraction. Archives of Oral Biology, 47, 701-707. http://dx.doi.org/10.1016/S0003-9969(02)00051-1

[18] Muhonen, A., Peltomäki, T., Knuuti, J., Raitakari, O. and Happonen, R.P. (2002) Osteoblastic Activity of the Rabbit Temporomandibular Joint during Distraction Osteogenesis Assessed by $\left[{ }^{18} \mathrm{~F}\right]$ Fluoride Positron Emission Tomography. European Journal of Oral Sciences, 110, 144-148. http://dx.doi.org/10.1097/01.PRS.0000163322.22436.3B 
[19] La Scala, G.C., O’Donovan, D.A., Yeung, I., et al. (2005) Radiation-Induced Craniofacial Bone Growth Inhibition: Efficacy of Cytoprotection Following a Fractionated Dose Regimen. Plastic \& Reconstructive Surgery, 115, 1973-1985. http://dx.doi.org/10.1097/01.PRS.0000163322.22436.3B

[20] Girod, A., Roger, T., Breton, P. and Bouletreau, P. (2005) Experimental Study of Mineralization in Mandibular Bone Distraction with Irradiation during the Consolidation Phase. Journal of Cranio-Maxillofacial Surgery, 33, 386-394. http://dx.doi.org/10.1016/j.jcms.2005.07.005

[21] Shao, Z., Liu, B.L., Liu, Y.P., et al. (2006) Distraction Osteogenesis in the Irradiated Rabbit Mandible. Journal of Plastic, Reconstructive \& Aesthetic Surgery, 59, 181-187. http://dx.doi.org/10.1016/j.bjps.2005.04.032

[22] Clark, C.L., Strider, J., Hall, C., et al. (2006) Distraction Osteogenesis in Irradiated Rabbit Mandibles with Adjunctive Hyperbaric Oxygen Therapy. Journal of Oral and Maxillofacial Surgery, 64, 589-593. http://dx.doi.org/10.1016/j.joms.2005.12.027

[23] Springer, I.N., Niehoff, P., Açil, Y., et al. (2008) BMP-2 and bFGF in an Irradiated Bone Model. Journal of CranioMaxillofacial Surgery, 36, 210-217. http://dx.doi.org/10.1016/j.jcms.2007.09.001

[24] Niehoff, P., Springer, I.N., Açil, Y., et al. (2008) HDR Brachytherapy Irradiation of the Jaw-As a New Experimental Model of Radiogenic Bone Damage. Journal of Cranio-Maxillofacial Surgery, 36, 203-209. http://dx.doi.org/10.1016/j.jcms.2008.01.003

[25] Fenner, M., Park, J., Schulz, N., et al. (2010) Validation of Histologic Changes Induced by External Irradiation in Mandibular Bone. An Experimental Animal Model. Journal of Cranio-Maxillofacial Surgery, 38, 47-53. http://dx.doi.org/10.1016/j.jcms.2009.07.011

[26] Williamson, R.A. (2007) An Experimental Study of the Use of Hyperbaric Oxygen to Reduce the Side Effects of Radiation Treatment for Malignant Disease. International Journal of Oral \& Maxillofacial Surgery, 36, 533-540. http://dx.doi.org/10.1016/j.ijom.2007.03.003

[27] Brasseur, M., Brogniez, V., Grégoire, V., et al. (2006) Effects of Irradiation on Bone Remodelling around Mandibular Implants: An Experimental Study in Dogs. International Journal of Oral and Maxillofacial Surgery, 35, 850-855. http://dx.doi.org/10.1016/j.ijom.2006.03.016

[28] Gantous, A., Phillips, J.H., Catton, P. and Holmberg, D. (1994) Distraction Osteogenesis in the Irradiated Canine Mandible. Plastic \& Reconstructive Surgery, 93, 164-168. http://dx.doi.org/10.1097/00006534-199401000-00025

[29] Brogniez, V., D’Hoore, W., Gregoire, V., Munting, E. and Reychler, H. (2000) Implants Placed in an Irradiated Dog Mandible: A Morphometric Analysis. International Journal of Oral \& Maxillofacial Implants, 15, 511-518.

[30] Schon, R., Ohno, K., Kudo, M. and Michi, K. (1996) Peri-Implant Tissue Reaction in Bone Irradiated the Fifth Day after Implantation in Rabbits: Histologic and Histomorphometric Measurements. International Journal of Oral \& Maxillofacial Implants, 11, 228-238.

[31] Jegoux, F., Aguado, E., Cognet, R., et al. (2010) Alveolar Ridge Augmentation in Irradiated Rabbit Mandibles. Journal of Biomedical Materials Research Part A, 93, 1519-1526.

[32] Pinholt, E.M. and Kwon, P.H. (1992) The Effect of Therapeutic Radiation on Canine Alveolar Ridges Augmented with Hydroxylapatite. Journal of Oral and Maxillofacial Surgery, 50, 250-254. http://dx.doi.org/10.1016/0278-2391(92)90321-P

[33] Lorente, C.A., Song, B.Z. and Donoff, R.B. (1992) Healing of Bony Defects in the Irradiated and Unirradiated Rat Mandible. Journal of Oral and Maxillofacial Surgery, 50, 1305-1309. http://dx.doi.org/10.1016/0278-2391(92)90232-0

[34] Klotch, D.W., Ganey, T., Greenburg, H. and Slater-Haase, A. (1996) Effects of Radiation Therapy on Reconstruction of Mandibular Defects with a Titanium Reconstruction Plate. Otolaryngology, Head and Neck Surgery, 114, 620-627. http://dx.doi.org/10.1016/S0194-5998(96)70256-5

[35] Tamplen, M., Trapp, K., Nishimura, I., et al. (2011) Standardized Analysis of Mandibular Osteoradionecrosis in a Rat Model. Otolaryngology, Head and Neck Surgery, 145, 404-410. http://dx.doi.org/10.1177/0194599811400576

[36] Ubios, A.M., Piloni, M.J. and Cabrini, R.L. (1992) Mandibular Growth and Tooth Eruption after Localized X-Radiation. Journal of Oral and Maxillofacial Surgery, 50, 153-156. http://dx.doi.org/10.1016/0278-2391(92)90361-3 